\title{
Bioelectric impedance analysis versus prediction equations for percent body fat in healthy nige- rian adults: correlation or conflict
}

\author{
Chidozie Emmanuel Mbada BMR ${ }^{1,2}{ }_{\text {ABCDEF}}$ Rufus Adesoji Adedoyin BMR ${ }^{1}{ }_{\text {ADEP' }}$ \\ Adebusola Oluwasanmi BMR PT ${ }_{\text {ABDEF }}^{1}$ Taofeek Olumide Awotidebe BMR M.Ed, ${ }^{1}$ ADEF
}
${ }^{1,2}$ Department of Medical Rehabilitation, College of Health Sciences, Obafemi Awolowo University, Ile - Ife, Nigeria.
${ }^{2}$ African Population and Health Research Center, Nairobi Kenya.

\begin{abstract}
Background and objective: There is dearth of studies on the validation of equations for predicting Percent Body Fat (PBF) in sub-Saharan Africa. This study compared Bio-electrical Impedance Analysis (BIA) estimated $\mathrm{PBF}$ and $\mathrm{PBF}$ predicted from equations.

Materials and Methods: 1,350 volunteers whose ages ranged between 18 and 65 years participated in this study. Anthropometric parameters and indices were assessed following standardized procedures. BIA was used to estimate PBF based on standard formulae. Deurenberg -\#1, Deurenberg-\#2, Gallagher and Jackson-Pollock equations were used to compute PBF. Data was analyzed using descriptive and inferential statistics. Alpha was set at 0.05 .

Results: The mean values for PBF obtained from BIA, Deurenberg \#1, Deurenberg \#2, Gallagher, Jackson-Pollock and the present study's equations were $21.5 \pm 9.3,11.5 \pm 6.76,9.3 \pm 7.09,9.4 \pm 7.38$, and 7.9 \pm 7.87 . BIA estimated PBF was significantly higher than predictive PBF $(\mathrm{p}=0.001)$. BIA estimated PBF was significantly correlated with each of Deurenberg \#1 ( $r=0.122 ; \mathrm{p}=0.001)$; Deurenberg-\#2 ( $\mathrm{r}=0.102 ; \mathrm{p}=0.001)$; Gallagher $(\mathrm{r}=0.080$; $p=0.001)$; Jackson-Pollock ( $r=0.060 ; p=0.016)$ and the present study's $(r=0.997 ; p=0.001)$ equations. Socio-demographic and anthropometric variable except WHR were significantly correlated with BIA estimated PBF $(\mathrm{p}<0.05)$. Age, sex and BMI could significantly predict PBF at $68.3 \%$ level of variability.

Conclusion: There were significant inverse but weak relationships between BIA estimated PBF and each of Deurenberg-\#1, Deurenberg-\#2, Jackson-Pollock and Gallagher prediction equation. The BIA estimated PBF was significantly higher than predicted PBF. Socio-demographic and anthropometrical variables were significantly determinants of BIA estimated PBF. The prediction equation derived from this study provides an easy method of estimating PBF but not without significant error as indicated by level of variability in the standard error of measurement.
\end{abstract}

Key words: Percent body fat, bioelectric impedance analysis, prediction equation, Nigeria

\section{Introduction}

Literature is replete with a range of options including anthropometric, physical, chemical, and electrical means to evaluate body composition. Some of the body composition assessment methods include underwater weighing, dual-energy $\mathrm{X}$-ray absorptiometry, magnetic resonance imaging, air-displacement plethysmography and skinfold thickness measurement [1-4]. A number of these methods have limited applicability and clinical usability as they are often difficult to administer, complex, costly, time consuming and requires specialized training and skills $[1,5,6]$.

Accurate assessment of the presence of excessive body fat is believed to be the first step in initiating correct preventive and treatment programmes $[3,5]$. Although, there is no ubiquitous method for the assessment of excessive body fat $[1,3,5]$, however, the classical variables of anthropometry such BMI is extensively used as simple index of body adiposity and surrogate measure of obesity in both clinical and research settings [610]. The drawbacks of this classical anthropometry approach included its inability to take into account factors such as frame size, muscular mass and distribution of body fat $[8,9,11]$ and it does not fully adjust for the effects of morphological variations across ethnic and racial divides [12].

Consequently, other anthropometric measures of central adiposity such as waist circumfe- 
rence, waist-to-hip ratio, and waist-height-ratio; and the Bioelectrical Impedance Analysis (BIA) are the most preferred indicators of total body fatness in clinical practice and research $[4,5,13-15]$. The BIA is the method of body fat assessment that take advantage of the principle of body tissue conductivity of electricity based on the water and dissolved electrolyte content by using a small, alternating, single-frequency current that passes through electrodes applied to extremities of the body or contact sensors to measure impedance or opposition to the flow of the electric current through body tissues which can then be used to calculate an estimate of total body water $[16,17]$. There is increasing studies on the psychometric properties of BIA in the assessment of body fat in health and disease across different population $[18,19]$.

Other than the anthropometrical and electrical methods, studies to develop and validate predictive models from the anthropometric $[20,21]$ and BIA [22-24] equations to predict body composition are populating [20-24]. Most of these equations are reported to have excellent psychometric properties and are recommended for use as indirect method of determining body composition in epidemiologic and clinical studies [20-24]. However, most of the equations have been shown to be dependent on factors not limited to age [25], gender [25] and ethnicity [26, 27]. Unfortunately, most of these prediction equations originated among Europeans, Caucasians and Asians who differ significantly in anthropometric and morphologic characteristics from sub-Saharan Africans. Despite, recommendations for validation of body composition estimates by BIA compared with the indirect method involving predictive formulae in order to establish the universality of their application [28], these equations have not been widely validated in sub-Saharan Africa. The objectives of this study was to compared BIA estimated Percent Body Fat (PBF) and PBF predicted from equations involving Deurenberg -\#1, Deurenberg -\#2, Gallagher and Jackson-Pollock. In addition, this study investigated the influence of demographic and anthropometric variables on BIA estimated PBF.

\section{Materials and methods}

The Ethical Review Committee of the Obafemi Awolowo University Teaching Hospitals Complex (OAUTHC), Ile-Ife, Nigeria gave approval for this study. Informed consent was obtained from every consecutive participant after the purpose of the study was fully disclosed. A total of 1,350 apparently healthy volunteers ( 778 males and 572 females) who were 18 years and older participated in this study.

The students' participants in this study were recruited randomly from the Obafemi Awolowo University (OAU), Ile-Ife, Nigeria using random sampling technique. Nine faculties including Administration, Basic Medical Sciences, Clinical Sciences, Law, Pharmacy, Sciences, Social Sciences and Technology were randomly selected among the thirteen faculties in the university using fishbowl technique. From the selected faculties, those that have only one degree awarding department were automatically included in the study while two departments each were randomly selected from those faculties with more than one degree awarding departments. The selected departments were Accounting, Biochemistry, Economics, Electrical Engineering, Law, Mechanical Engineering, Medicine, Medical Rehabilitation, Microbiology, Pharmacy, Psychology, and Sociology and Anthropology. The non-students' participants included consecutive academic, clinicians, administrative and support staffs of the OAU and OAUTHC respectively. The OAU academic and administrative staff that participated in this study were recruited from same departments as the students. The recruitment of staff from the OAUTHC was carried out separately. Staff were recruited from the departments of Medical Rehabilitation, Accounts, Maintenance and the Administration unit. Participants for the study were determined for eligibility via interview to ensure that they satisfied the selection criteria. Exclusion criteria for the study were a positive history of endocrinologic and/or metabolic condition; being pregnant; participation in high-intensity regular exercise or elites sports; and a presence of metallic implant or cardiac pacemaker in situ or other contraindications to the use of BIA.

Anthropometric parameters assessed in the study included height, weight, body mass index (BMI), waist circumference, hip circumference, waist-hip ratio and waist-height ratio. A height-meter (Seca Alpha Brand) calibrated from 0 to $200 \mathrm{~cm}$ was used to measure the height of each participant to the nearest $0.1 \mathrm{~cm}$. The participants' heels, back and occiput touched the stadiometer scale with the participants looking straight ahead during measurement. Body weight in light clothes was measured to the nearest $0.1 \mathrm{~kg}$ using a weighing scale (Inter Ikea systems B.V. 1999) calibrated from 0 to $120 \mathrm{~kg}$ with the participant in standing position with shoes off. Tape measure was used to measure the waist cir- 
cumference of the participants around the body at the level of the umbilical cord with the participants asked to remove clothing materials around the body part. Tape measure was used to measure the participants' hip circumference at the level of the greater trochanter with the participants in minimal clothing materials around the part. Waist-to-hip ratios were obtained by dividing waist circumference by hip circumference while waist-to-height ratios were obtained by dividing waist circumference by height. Socio-demographic variables were obtained using a proforma.

Bioelectric Impedance Analysis (BIA) machine (Omron BF306; Model HBF-306-E CE, Japan) was used to estimate PBF. The participants were instructed to remove all metal objects, e.g. earrings, chains, wrist watches. They were instructed to stand erect with the two feet together and also to hold the machine in both hands such that the palms covered the metal surfaces of the instrument. They were then instructed to hold the arms straight at $90^{\circ}$ of shoulder flexion. Dryness of the palms was ensured by using a dry towel for cleaning if the palms were wet, and by also making sure that the participants did not have hyperhidrosis. The height, weight, age and sex of the participants were fed into the micro data processor of the instrument, and the start button was switched on. The participants were then asked to stand still till a new set of data was displayed on the meter [29].

Predictive equations used to predict PBF in this study included.

Deurenberg [7] -\#1: (1.20 x BMI $)+(0.23 \mathrm{x}$

Age) - (10.8 x gender) - 5.4

- Deurenberg [8] -\#2: (1.29 x BMI $)+(0.20 \times$ Age $)$

- (11.4 x gender $)-8.0$

- Gallagher [30]: (1.46 x BMI) + (0.14 x Age) - (11.6

$\mathrm{x}$ gender) - 10

- Jackson-Pollock [31, 32]: (1.61 x BMI) + (0.13 x Age) - (12.1 x gender) - 13.9

\section{Data Analysis}

The data was summarized using descriptive statistics of mean and standard deviation. Independent $\mathrm{t}$-test was used to compare PBF between male and female participants. Pearson product moment correlation was used to determine the correlates of PBF. Scatter plot with linear curve estimation was use to depict the agreement between BIA estimated PBF and equations predicted PBF. Multiple regression analysis was used to develop a predictive model in this study. Data was completed using Sta- tistical Package for Social Sciences (SPSS) software version 16. Alpha level was set at $\alpha=0.05$.

\section{Results}

The age range of the participants was between 18 and 65 years. Age and general characteristics of all the participants and by gender is presented in table 1.

Table 1: Age and general characteristics of all the participants and by gender

\begin{tabular}{|c|c|c|c|c|c|c|}
\hline \multirow[b]{2}{*}{ Variables } & \multirow{2}{*}{$\begin{array}{l}\text { Male } \\
\qquad X \pm S D\end{array}$} & \multicolumn{5}{|l|}{ Female } \\
\hline & & $\mathrm{X} \pm \mathrm{SD}$ & & t-cal & $\mathrm{p}$-val & le All participants \\
\hline Age (years) & $24.1 \pm 5.83$ & $23.4 \pm 5.91$ & 12.350 & 0.61 & $523.8=$ & 5.87 \\
\hline Height $(\mathrm{m})$ & $1.7 \pm 0.08$ & $1.6 \pm 0.07$ & 16.710 & $\begin{array}{ll}0 & 0.005 \\
0\end{array}$ & $91.7 \pm$ & \\
\hline Weight $(\mathrm{Kg})$ & $64.0 \pm 8.46$ & $61.1 \pm 10.0$ & & 5.871 & 0.0 & $162.8 \pm 9.28$ \\
\hline $\operatorname{BMI}\left(\mathrm{Kg} / \mathrm{m}^{2}\right)$ & $21.9 \pm 3.05$ & $22.8 \pm 3.93$ & 3.725 & 0.001 & $122.3=$ & 3.48 \\
\hline PBF (BIA) & $16.3 \pm 6.96$ & $28.6 \pm 7.23$ & & 31.475 & 0.941 & $21.5 \pm 9.35$ \\
\hline $\mathrm{WC}(\mathrm{m})$ & $0.7 \pm 8.46$ & $0.8 \pm 9.45$ & 2.003 & 0.1 & & $0.78 \pm 0.88$ \\
\hline $\mathrm{HC}(\mathrm{m}) \quad 0.8 \pm$ & \pm 9.90 & $0.9 \pm 9.26 \quad 3.923$ & 0.147 & $70.87 \pm c$ & 0.98 & \\
\hline WHR & $0.9 \pm 0.16$ & $0.9 \pm 0.12$ & 4.240 & 0.005 & $90.9 \pm$ & \\
\hline
\end{tabular}

The mean age, BMI, BIA estimated PBF, WC, HC, and WHR was $23.8 \pm 5.8$ years, $22.3 \pm 3.48$ $\mathrm{Kg} / \mathrm{m} 2,21.5 \pm 9.35,0.78 \pm 0.88,0.87 \pm 0.98$ and 0.9 \pm 0.16 respectively. The independent -test comparison showed that $\mathrm{WC}, \mathrm{HC}$ and WHR of the male and female participants were comparable $(\mathrm{p}>0.05)$. However, the females had significantly higher BMI than the male counterparts $(\mathrm{p}<0.05)$.

Each of the scatter plots showed direct relationship between the PBF and the predictive equations (figures 1, 2, 3, 4 and 5). Scatter plots were used to highlight the linearity of the Cartesian co -ordinates that formed the variables that were correlated. Pearson product moment correlation analysis incorporated into the figures showed a significant correlation between BIA estimated PBF and each of Deurenberg (BIA) $(\mathrm{r}=0.122, \mathrm{p}<0.001)$; Deurenberg (BMI) $(\mathrm{r}=0.102, \mathrm{p}<0.001)$; Gallagher $(\mathrm{r}$ $=0.080, \mathrm{p}<0.001)$; Jackson-Pollock $(\mathrm{r}=0.060, \mathrm{p}$ $<0.016)$ and the present study's ( $\mathrm{r}=0.997 ; \mathrm{p}=0.001)$ equations. Table 2 shows the Pearson product moment correlation between BIA estimated PBF and participants general characteristics. Socio-demographic and anthropometric variable except WHR were significantly correlated with BIA estimated PBF $(\mathrm{p}<0.05)$.

Table 3 showed the One-Way ANOVA comparison of the BIA estimated PBF and the predictive equations. From the result, a significant difference was found in the F-ratio. Post-Hoc analysis was used to elucidate where the difference found in 
Table 2: Correlation matrix between PBF and each of age and selected anthropometric parameters

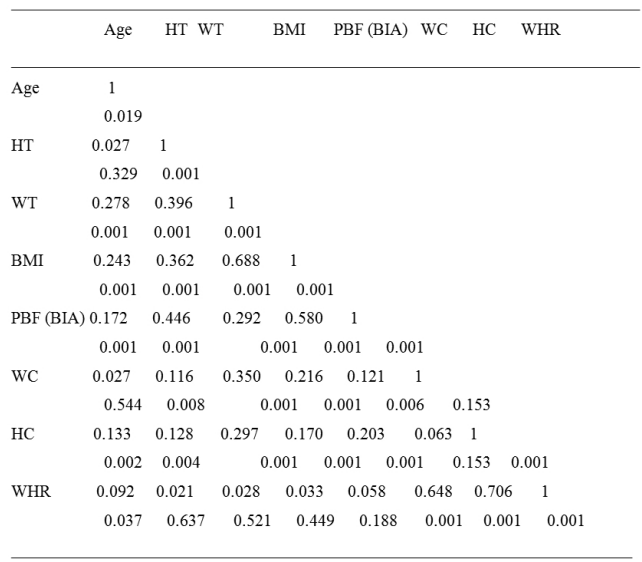

$\mathrm{HT}=$ height WT $=$ weight BMI = body mass index; $\mathrm{PBF}=$ percent body fat; $\mathrm{BIA}=$ bioelectric impedance analysis; $\mathrm{WC}=$ waist circumference; $\mathrm{HC}=$ hip circumference; $\mathrm{WHR}$ = waist-hip-ratio.

the F-ratio lie. The result showed that BIA estimated PBF was significantly higher $(\mathrm{p}<0.05)$ than the values obtained from the predictive equations. No significant difference was found in the PBF values estimated using Deurenberg and Gallagher equations (9.3 \pm 7.09 vs. $9.4 \pm 7.38 ; p>0.05)$. renberg (BIA), Deurenberg (BMI), Gallagher and Jackson-Pollock. The study found that BIA estimated PBF was significantly higher than equation predicted PBF. It was found that the Jackson-Pollock prediction equation yielded the least PBF mean value. Mazariegos et al [33] in a similar study submitted that the Jackson-Pollock prediction equation has a tendency to underestimate body fat. Overall, this study showed that predicted PBF where significantly lower than BIA estimated PBF. Similar findings have been reported in some other studies [34-37].

Kupper et al [35] reported that prediction equations generally underestimate PBF especially in females than males. The validity of prediction equations has been reported to be different among ethnic groups [38-40]. Therefore, it has been reported that use and applicability of prediction formulae developed in other populations is limited in other ethnic groups [26, 27, 41]. The differences observed between estimated and predicted PBF could be due in part to variation in pattern of fat distribution in the population from which the equations were de-

Table 3: Comparison of PBF estimated using BIA and Prediction Equations

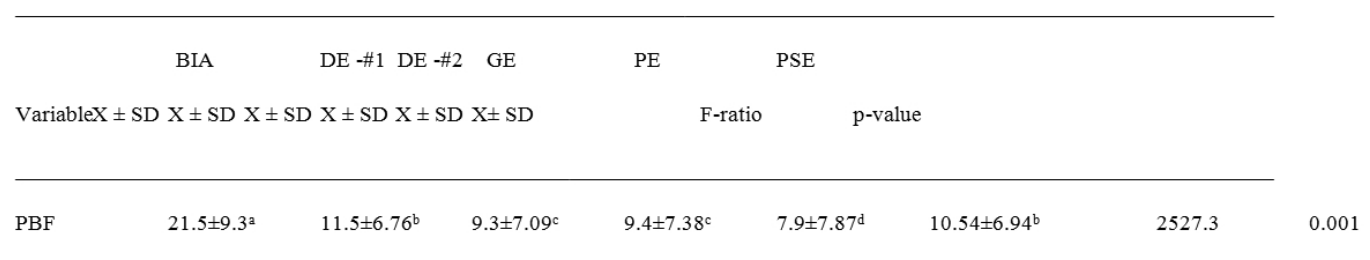

Superscript $(\mathrm{a}, \mathrm{b}, \mathrm{c}, \mathrm{d})$ - For a particular variable, mode means with different superscripts are significantly $(\mathrm{p}<0.05)$ different. Mode means with the same superscript are not significantly $(p>0.05)$ different.

BIA = Bioelectric Impedance Analysis; Deurenberg-\#1 Equation; Deurenberg-\#2 Equation; Gallagher Equation; Jackson-Pollock Equation; PBF = Percent Body Fat; PSE = The Present Study Equation

Multiple regression model was used to develop a predictive equation from this study. From this study, Age, Sex and BMI were significant predictors of $\mathrm{PBF}$. The regression equation for predicting $\mathrm{PBF}$ is $-\mathrm{Y}=\mathrm{B} 0+\mathrm{B} 1 \times 1+\mathrm{B} 2 \times 2+\mathrm{B} 3 \times 3$, Where $\mathrm{Y}$ is $\mathrm{PBF}$; $\mathrm{B} 0$ is a constant; $\mathrm{B} 1-\mathrm{B} 3$ are co-efficient of the independent variables. $\mathrm{Y}=-26.960+(0.148 \mathrm{x}$ $1)+(11.267 \times 2)+(1.296 \times 3) . \quad Y=-26.960+0.148$ (Age) +22.534 (Sex) +3.888 (BMI). The level of variability for the prediction equation was $68.3 \%$ (i.e. $\mathrm{R} 2=0.683)$.

\section{Discussion}

This study compared BIA estimated PBF and PBF predicted from equations involving Deu- veloped [42], measurement error [35] and variation in body water [41].

There was significant correlation between BIA estimated PBF and each of the prediction equations. However, the relationships were somewhat weak and inverse. The negative and weak association of all prediction equations with BIA estimated PBF may indicate poor applicability of these prediction equations developed in other population to Nigerians. Furthermore, the inverse correlations observed between estimated and predicted PBF could indicate under-estimation of PBF using these equations. Ideally, a prediction equation should be sufficiently precise to detect changes in the predicted variables in PBF [43], however, these predictive 
equations are believed to be limited in their generalizability to other populations because of the potential influence of race [44], age [25] and ethnicity $[26,27,41]$. Nonetheless, the use of regression equations in estimating body fats is populating in literature. The findings of this study also show that predictive equations were directly and strongly correlated with one another. Strong significant correlation was observed between Deurenberg - $\# 2$ and Gallagher ( $r=0.997)$; Gallagher and Jackson-Pollock $(r=0.999)$ and Deurenberg -\#2 and Jackson -Pollock $(r=0.995)$ prediction equations.

The results of this study showed that there was a strong influence of sex on PBF. The finding of this study on higher PBF among females is largely consistent with literature $[33,35,45,46]$. There was significant relationship between BIA estimated PBF and each of height, weight, BMI, waist circumference and hip circumference. However, there was no significant correlation between PBF and waist-hip -ratio. According to de Menezes et al [47], waist-hip -ratio demonstrated a weak and non-significant correlation with PBF. Similar studies have suggested that waist-hip-ratio is not a strong indicator of body fat [47.48]. On the other hand, waist circumference correlated moderately and significantly with PBF in this study. Freitas et al [49] described waist circumference as the best anthropometric index for diagnosing adiposity. This study showed that there was a strong relationship between age and PBF. This agreed with the outcome of a study by Meeuwsen et al [50] where it was discovered that measures of adiposity increases with age. However, this influence of age on body adiposity as observed in this study was more pronounced in females than in males corroborating the findings of Meeuwsen et al [50]. Several other previous studies have come up with similar findings [51-54].

This study is an important investigation into the applicability of the prediction equations as an indirect methods for body composition assessment among Nigerian adult populations. However, the results of this study implicate that foreign prediction equations should be used with caution as they may potentially under-estimate PBF. This submission was hinged on the strength of correlation between BIA estimated PBF and the predicted PBF from the equation developed from this study. The present study does not assume that the BIA perfectly estimates body fats. As some studies have reported underestimation of body fat using BIA as compared with other methods such as skinfold thickness, Dual-energy X-Ray Absorptiometry (DXA) [1-4].
The underestimation of body fats by BIA has been implicated on anthropometric and morphological disproportion in body segments [20-22], in relation to body water to total body impedance [55]. Therefore, if BIA under-estimates body fats as reported in literature, prediction equations seem to under-estimates much more. However, a potential limitation of this study is the heterogeneity of its samples as the volunteers were screened on the basis of being lean or obese even though such participants were few in this study.

\section{Conclusion}

There were significant inverse but weak relationships between BIA estimated PBF and each of Deurenberg-\#1, Deurenberg-\#2, Jackson-Pollock and Gallagher prediction equation. The BIA estimated PBF was significantly higher than predicted PBF. Socio-demographic and anthropometrical variables were significantly determinants of BIA estimated PBF. The prediction equation derived from this study provides an easy method of estimating PBF but not without significant error as indicated by level of variability in the standard error of measurement.

\section{References:}

1. Duren DL, Sherwood RJ, Czerwinski SA, Lee M, Choh AC, Siervogel RM, Chumlea WC. Body Composition Methods: Comparisons and Interpretation. J Diabetes Sci Technol. 2008, 2;6: 1139-1146.

2. Ellis KJ. Human body composition: In vivo methods. Physiological Reviews. 2000, 80: 649-680.

3. Sung RYT, So HK, Choi KC, Li AM, Yin J, Nelson EAS. Body fat measured by bioelectrical impedance in Hong Kong Chinese children. Hong Kong Med J 2009; 15:110-117.

4. Goss F, Robertson R, Williams A, Sward K, Abt K, Ladewig M, Timmer J, Dixon C. A comparison of skinfolds and leg-to-leg bioelectrical impedance for the assessment of body composition in children. Dynamic Medicine 2003, 26;2(1):5

5. Sung RY, Yu CC, Choi KC, et al (2009). Waist circumference and obesity mass index in Chinese children: cutoff values for predicting cardiovascular risk factors. Int J Obes 2009, 31:550-558.

6. Lee SY, Gallagher D. Assessment methods in human body composition. Curr Opin Clin Nutr Metab Care. 2008, 11(5): 566-572.

7. Deurenberg P, Weststrate JA, Seidell JC. Body mass index as a measure of body fatness: age- and sex-specific prediction formulas. Br J Nutr. 1991, 65(2):105-114. 
8. Deurenberg P, Yap M, Van Staveren WA. Body mass index and percent body fat: a meta analysis among different ethnic groups. Int. J. Obes. 1998, 22; 1164-1171. 9. Deurenberg-Yap M, Schmidt G, Staveren WA, Deurenberg P. The paradox of low body mass index and high body fat percent among Chinese, Malays and Indians in Singapore. Int. J. Obes Relat Metab Disord. 2000, 24, 1011-1017.

10. Baumgartner RN, Heymsfield SB, Lichtman S, Wang J, Pierson RN JR. Body composition in elderly people: effect of criterion estimates on predictive equations. Am J Clin Nutr 1991; 53:1345.

11. Deurenberg P. Universal cut-off BMI points for obesity are not appropriate. Br. J. Nutr. 2001; 85: 135136.

12. National Health Services. Body Mass Index as a measure of obesity. [Internet] 2009. [Cited 2014 Aug 12]. Available from: http://www.noo.org.uk.

13. Lean MEJ, Han TS, Morrison CE.Waist circumference as a measure for indicating need for weight management. Brit Med J. 1995; 311: 158-161.

14. Foucan L, Hanley J, Deloumeaux J, Suissa S. Body mass index and waist circumference as screening tools for cardiovascular risk factors in Guadeloupean women. J Clin Epid 2002; 55: 990-996.

15. Wang J, Deurenberg P. The validity of predicted body composition in Chinese adults from anthropometry and bio-electrical impedance in comparison with densitometry. Br J. Nutr, 1996; 76, 175-182.

16. Kyle UG, Ingvar B, De Lorenzo AD, Deurenberg P, Elia M, Manuel Gómez J, Lilienthal Heitmann B, Kent-Smith L. et al. Bioelectrical impedance analysis--part I: review of principles and methods. Clin Nutr. 2004; 23:1430-1453.

17. Cornier M-A, Després J-P, Davis N, Grossniklaus DA, Klein S, Lamarche B, Lopez-Jimenez F, Rao G, St-Onge M-P, Towfighi A, Poirier P; on behalf of the American Heart Association Obesity Committee of the Council on Nutrition, Physical Activity and Metabolism, Council on Arteriosclerosis, Thrombosis and Vascular Biology, Council on Cardiovascular Disease in the Young, Council on Cardiovascular Radiology and Intervention, Council on Cardiovascular Nursing, Council on Epidemiology and Prevention, Council on the Kidney in Cardiovascular Disease, and Stroke Council. Assessing adiposity: a scientific statement from the American Heart Association. Circulation. 2011, 124; 1996-2019. 18. de Waart FG, Li R, Deurenberg P. Comparison of body composition assessments by bioelectrical impedance and by anthropometry in premenopausal Chinese women. Br J Nutr. 1993; 69:657.

19. Stolarczyk LM, Heyward VH, Hicks VL, Baumgartner RN. Predictive accuracy of bioelectrical impedance in estimating body composition of Native American women. Am J Clin Nutr. 1994; 59:964.

20. Dezenberg CV, Nagy TR, Gower BA, Johnson R, Goran MI: Predicting body composition from anthropometry in pre-adolescent children. Int J Obes Relat Metab Disord. 1999; 23:253-259.
21. Visser M, Heuvel Ev, Deurenberg P. Prediction equations for the estimation of body composition in the elderly using anthropometric data. Br J Nutr 1994; 71: 823-833.

22. Sun SS, Chumlea WC, Heymsfield SB, Lukaski HC, Schoeller D, Friedl K, Kuczmarski RJ, Flegal KM, Johnson CL, Hubbard VS. Development of bioelectrical impedance analysis prediction equations for body composition with the use of a multicomponent model for use in epidemiologic surveys. Am J Clin Nutr. 2003;77(2):331-40.

23. Davies PSW, Preece MA, Hicks CJ, Halliday D. The prediction of total body water using bioelectrical impedance in children and adolescents. Ann Hum Biol. 1988; 15:237-240.

24. Deurenberg P, van der Kooy K, Leenen R,Weststrate JA, Seidell JC. Sex and age specific prediction formulas for estimating body composition from bioelectric impedance: a cross-validation study. Int J Obes, 1991; 15:17-25.

25. Jackson AS, Stanforth PR, Gagnon J Rankinen T, Leon AS, Rao DC, Skinner JS, Bouchard C, Wilmore JH: The effect of sex, age and race on estimating percentage body fat from body mass index: the Heritage Family Study: Int J Obes Relat Metab Disord, 2002; 26(6): 789-96.

26. Nightingale CM, Rudnicka AR, Owen CG, Donin AS, Newton SL, Furness CA, Howard EL, Gillings RD, Wells JCK, Cook DG, Whincup PH. Are Ethnic and Gender Specific Equations Needed to Derive Fat Free Mass from Bioelectrical Impedance in Children of South Asian, Black African-Caribbean and White European Origin? Results of the Assessment of Body Composition in Children Study. PLoS One. 2013; 8(10): e76426.

27. Jackson AS, Ellis KJ, McFarlin BK, Sailors MH, Bray MS. Cross-validation of generalised body composition equations with diverse young men and women: the Training Intervention and Genetics of Exercise Response (TIGER) Study. Br J Nutr. 2009; 101(6): 871-878. 28. Chertow GM, Lowrie EG, Lew NL: Bioelectrical impedance analysis predicts survival in hemodialysis patients. J Am Soc Nephrol. 1996; 7:1442.

29. Mbada CE, Ayanniyi O, Adedoyin RA. Influence of relative adiposity on static back extensor muscle endurance in apparently healthy adults. Hong Kong Physiother J. 2008; 26:2-8.

30. Gallagher D, Visser M, Sepulveda D, Pierson RN, Harris T, Heymsfield SB. How useful is body mass index for comparison of body fatness across age, sex and ethnic group? Am J Epidemiol. 1996; 143: 228-239.

31. Jackson AS, Pollock ML, Ward A. Generalized equations for predicting body density of women. Med Sci Sports Exercise. 1980; 12:175-182.

32. Jackson AS. Research design and analysis of data procedures for predicting body density. Med Sci Sports Exercise. 1984; 16:616-620.

33. Mazariegos M, Wang ZM, Gallagher D, Baumgartner RN, Allison DB, Wang J, Pierson RN, Jr, Heymsfield SB. Differences between young and old fe- 
males in the five levels of body composition and their relevance to the two-compartment chemical model. J Gerontol. 1994; 49:M201-M208.

34. McNeill G, Fowler PA, Maughan RJ, McGaw BA, Fuller MF, Gvozdanovic D, Gvozdanovic S. Body fat in lean and overweight women estimated by six methods. Br J Nutr. 1991; 65: 95-103.

35. Kupper J, Bartz M, Schultink JW, Lukito W, Deurenberg P: Measurements of body fat in Indonesian adults: comparison between a three - compartment model and widely used methods. Asia Pacific J Clin Nutr. 1998; 7(1): 49-54.

36. Lukaski HC, Johnson PE, Bolonchuk WW, Lykken GI. Assessment of fat-free mass using bioelectrical impedance measurements of the human body. Am J Clin Nutr. 1985; 41:810-817.

37. Lukaski HC. Methods for the assessment of human body composition: traditional and new. Am J Clin Nutr.1987; 46:537-556.

38. Aristizabal JC, Restrepo MT, Estrada A. Assessment of body composition in healthy adults by anthropometry and bioelectrical impedance. Biomedica. 2007; 27:216-224.

39. Wang J, Deurenberg P. The validity of predicted body composition in Chinese adults from anthropometry and bio-electrical impedance in comparison with densitometry. Br J Nutr.1996; 76: 175-182.

40. Willett K, Jiang R, Lenart E, Spiegelman D, Willett W. Comparison of bioelectrical impedance and BMI in predicting obesity-related medical conditions. Obesity. 2006; 14: 480-490.

41. Deurenberg P, Deurenberg-Yap M, Schouten FJM. Validity of total and segmental impedance measurements for prediction of body composition across ethnic population groups. Eur J Clin Nutr. 2002; 56:3:214-220.

42. Durnin JV, Womersley J. Body fat assessed from total body density and its estimation from skinfold thickness: Measurements on 481 men and women aged from 16 to 72 Years. Br J Nutr. 1974; 32(1):77-97.

43. Fried KE, Westphal KA, Marchitelli LJ, Patton JF, Chumlea WC, Guo SS. Evaluation of anthropometric equations to asess body-composition changes in young women. Am J Clin Nutr. 2001; 73(2): 268-275.

44. Amber O, Hassler J, Brogowski J, Bowen JC, Mayhew JL. Relationship Between Body Mass Index and Predicted PBF in College Men and Women. J Health, Physical Education, Recreation \& Dance. 2000; 10:23-29. 45. Horie LM, Barbosa-Silva MC, Torrinhas RS, de Mello MT, Cecconello I, Waitzberg DL. New body fat prediction equations for severely obese patients. Clin Nutr. 2008; 27(3):350-356.

46. Li YC, Li CI, Lin WY, Liu CS, Hsu HS, Lee CC, Chen FN, Li TC, Lin CC. Percentage of Body Fat Assessment Using Bioelectrical Impedance Analysis and Dual-Energy X-ray Absorptiometry in a Weight Loss Program for Obese or Overweight Chinese Adults. PLoS ONE. 2013; 8(4): e58272.
47. de Menezes MC, Souza Lopes AC, Cunha LP, Jansen AK, dos Santos LC. An Optimal Method for Measuring Body Fat in Overweight Individuals in Clinical Practice. Endocrinol Metab Synd. 2012; S2:002;1-5.

48. Giugliano R, Melo ALP. Diagnosis of overweight and obesity in schoolchildren: utilization of the body mass index international standard. J. Pediatr. (Rio J.). $2004 ; 80: 2$.

49. Freitas SN, Caiaffa WT, César CC, Cândido AP, Faria VA, Neto RM, Machado-Coelho GL. A comparative study of methods for diagnosis of obesity in an urban mixed-race population in Minas Gerais, Brazil. Public Health Nutr 2007; 10: 883-890.

50. Meeuwsen S, Horgan GW, Elia M. The relationship between BMI and percent body fat, measured by bioelectrical impedance, in a large adult sample is curvilinear and influenced by age and sex. Clin Nutr. 2010; 29(5): 560-566.

51. Aloia JF, Vaswani A, Ma R, Flaster E: Aging in women-the four-compartment model of body composition. Metabolism. 1996; 45:43-8.

52. Ellis KJ. Reference man and woman more fully characterized. Variations on the basis of body size, age, sex, and race. Biol Trace Elem Res. 1990; s26-7:385-400. 53. Mott JW, Wang J, Thornton JC, Allison DB, Heymsfield SB, Pierson Jr RN. Relation between body fat and age in 4 ethnic groups. Am J Clin Nutr. 1999; 69(5): 1007-1013.

54. Poehlman ET, Toth MJ, Bunyard LB, Gardner AW, Donaldson KE, Colman E, Fonong T, Ades PA. Physiological predictors of increasing total and central adiposity in aging men and women. Arch Intern Med. 1995; 155:2443-2448.

55. Fuller NJ, Elia M. Potential use of bioelectrical impedance of the whole body and of body segments for the assessment of body composition: comparison with densitometry and anthropometry. Eur J Clin Nutr. 1989; 43:779-792.

Acknowledgement: The authors wish to thank the African Population and Health Research Centre (APHRC), Nairobi, Kenya for providing technical support through the African Doctoral Dissertation Research Fellowship (ADDRF) Post-Doctoral Fellowship. ADDRF is funded by the International Development and Research Centre (IDRC), Canada.

\section{Correspondence address:}

Chidozie E. Mbada BMR PT PhD

Department of Medical Rehabilitation, College of Health Sciences. Obafemi Awolowo University, Ile -Ife, Nigeria.

E-mail:doziembada@yahoo.com. 